\title{
Is frequency of potato and white rice consumption associated with cardiometabolic risk factors in children and adolescents: the CASPIAN-V study
}

Fereshteh Baygi ${ }^{1}$, Mostafa Qorbani ${ }^{2,3^{*}}$ (D), Mohammad Esmaeil Motlagh ${ }^{4}$, Gita Shafiee ${ }^{3}$, Kourosh Nouri $^{5}$, Zeinab Ahadi ${ }^{3}$, Armita Mahdavi-Gorab ${ }^{3}$, Ramin Heshmat ${ }^{3}$ and Roya Kelishadi ${ }^{6}$

\begin{abstract}
Background: This study evaluated the association of frequency of potato and rice consumption with cardiometabolic risk factors in children and adolescents.

Methods: This nationwide cross-sectional survey was conducted on 14,400 children and adolescents. Fasting blood was obtained from a sub-sample of 4200 randomly selected students. Physical examination and laboratory tests were conducted under standard protocols. Metabolic Syndrome (Mets) was defined based on the Adult Treatment Panel III criteria modified for the pediatric age group. The self-reported frequency consumption of white rice and potato was reported on a daily or non-daily basis.

Results: The participation rate for the whole study and for blood sampling were 99 and 91.5\%, respectively. Overall, $49.4 \%$ of the participants were girls while $50.6 \%$ were boys. The frequency of daily consumption of white rice and potato was 84.4 and $21.3 \%$, respectively. In the multivariable linear regression model, daily consumption of potato increased body mass index ( $\beta$ : 0.05, SE: $0.20, p=0.010$ ), waist ( $\beta$ : 0.63 , SE: $0.24, p=0.008$ ), and hip circumferences ( $\beta$ : 0.62 , SE: $0.26, p=0.019$ ). Moreover, in the multivariable logistic regression, daily consumption of potato was significantly associated with an increased risk of overweight (OR: 1.21, 95\% Cl: $1.04-1.39, P=0.012)$. The potato and rice consumption had no statistically significant association with other cardiometabolic risk factors.

Conclusions: Daily consumption of potato was significantly associated with higher anthropometric measures, whereas rice consumption had no statistically significant association with cardiometabolic risk factors. Future research to examine the possible obesogenic effects of intake of potato on children and adolescents is recommended.
\end{abstract}

Keywords: Cardiometabolic risk factors, Metabolic syndrome, White Rice, Bread, Potato

\footnotetext{
* Correspondence: mqorbani1379@yahoo.com

${ }^{2}$ Non-communicable Diseases Research Center, School of Medicine, Alborz

University of Medical Sciences, Baghestan Blvd, Karaj 31485/56, Iran

${ }^{3}$ Chronic Diseases Research Center, Endocrinology and Metabolism

Population Sciences Institute, Tehran University of Medical Sciences, Tehran,

Iran

Full list of author information is available at the end of the article
}

C The Author(s). 2020 Open Access This article is licensed under a Creative Commons Attribution 4.0 International License, which permits use, sharing, adaptation, distribution and reproduction in any medium or format, as long as you give appropriate credit to the original author(s) and the source, provide a link to the Creative Commons licence, and indicate if changes were made. The images or other third party material in this article are included in the article's Creative Commons licence, unless indicated otherwise in a credit line to the material. If material is not included in the article's Creative Commons licence and your intended use is not permitted by statutory regulation or exceeds the permitted use, you will need to obtain permission directly from the copyright holder. To view a copy of this licence, visit http://creativecommons.org/licenses/by/4.0/. The Creative Commons Public Domain Dedication waiver (http://creativecommons.org/publicdomain/zero/1.0/) applies to the data made available in this article, unless otherwise stated in a credit line to the data. 


\section{Background}

Nutrition -related non-communicable diseases like overweight and obesity are increasing in Iran [1-3]. The prevalence of overweight and obesity in children of America, Europe, Western Pacific, and Southeast Asia is 31, 38, 27, and $22 \%$, respectively [4]. The development of cardiovascular diseases- as one of the main causes of death- is related to numerous early life risk factors such as overweight and obesity $[5,6]$. Childhood excess weight increases the risk of obesity or overweight in the later years [7]. Shifts in dietary pattern can have significant effects on weight changes in terms of excess weight in children and adolescents $[8,9]$. Longitudinal studies have shown that there is an association between dietary patterns and cardiovascular diseases [10, 11]. Numerous studies have been published showing an inverse association between the consumption of whole-grain foods and body weight so that consumption of whole grains can reduce hunger and increase satiety $[12,13]$. Based on the results of a national household consumption survey, major part of the Iranian diet is devoted to plant foods [12]. Also, bread and rice are recognized as a major source of carbohydrates in Persian diets [14]. In an Asian population like Japan, because of high consumption of rice, the risk of metabolic syndrome and other non-communicable diseases is increasing [15]. Type and quantity of carbohydrates can have some effects on increased risk of cardiovascular disease (CVD) and type 2 diabetes [16-18]. Since the prevalence of obesity and associated co-morbidities in children and adolescents of developing countries is increasing, studies should be conducted regarding dietary pattern and their association with cardiometabolic risk factors. Accordingly, the current study aimed to evaluate the association of frequency of potato and rice consumption with cardio-metabolic risk factors in Iranian children and adolescents.

\section{Methods}

This multi-centric cross-sectional study was conducted in 2015 as the fifth survey of a surveillance program entitled "Childhood and Adolescence Surveillance and PreventIon of Adult Non- communicable disease" (CASPIAN-V) study. Overall, 14,400 students aged 7-18 years were recruited. They were selected by multistage, stratified cluster sampling from urban and rural areas of 30 provinces of Iran. Overall, 480 students were selected from each province according to the living area (urban/rural) and school grade (primary/ secondary), proportional to size with equal sex ratio. Blood sample was obtained from a sub-sample of 4200 randomly selected students. The study protocol has been described in detail previously [19]. It is summarized here.

\section{Demographic data}

In the current study, two sets of questionnaires were used to collect data from the all students and their parents. Questionnaire from WHO-GSHS was translated into Persian, and then its validity and reliability were assessed [20]. Demographic data including age, sex, residence area, physical activity (PA), and family socioeconomic status (SES) were collected by trained health care providers. At least one of the parents was required to be present for answering the questions.

PA was assessed using a valid questionnaire [20]. One week prior to the study, the subjects answered the following two questions: 1) how many days were you physically active for $30 \mathrm{~min}$ per day during last week? (responses ranged from 0 to 7 days) 2) How much time per week do you spend in exercise classes at school? (answers ranged from 0 to 3 or more hours).

Screen time (ST) behavior was assessed by asking students questions about how long they spent on watching TV, working with computers, and playing video games. Mean ST of more than $2 \mathrm{~h}$ per day was considered high, as sedentary lifestyle [20].

SES was assessed using an approved method provided for the Progress in the International Reading Literacy Study (PIRLS) [19]. Variables like parents' education and job, type of home (private, rented), type of school (private, governmental), and family asset (e.g., personal computer and private car) were summarized under one main component. Then, SES score was estimated using the principle components analysis (PCA) method [21]. The main component was categorized into three levels. The first, second, and third levels were considered as low, moderate, and high SES, respectively.

\section{Physical measurements}

Anthropometric indices such as body mass index (BMI), wrist circumference (WrC), waist circumference (WC), neck circumference $(\mathrm{NC})$, and hip circumferences $(\mathrm{HC})$ were measured for all students. All measurements were done using a non-elastic tape with standard protocol. Blood pressure (BP) was measured with the students in the arm position using a mercury sphygmanometer with an appropriate cuff size. It was measured twice at $15 \mathrm{~min}$ intervals. Systolic and diastolic blood pressure (SBP, DBP) was recorded and the average was recorded [22].

Rice and potato consumption were recorded using non-quantitative food frequency questionnaire (FFQ). In this questionnaire, the students reported the frequency of each food item as daily, weekly, seldom or never. For statistical analysis, the frequency consumption of rice and potato (daily or non-daily) was considered as weekly, seldom or never) consumption. Foods with a high content of sugar, salt, saturated fats and trans fats, and sugar sweetened beverages were considered as low nutrient-dense foods (LNDF).

\section{Blood sampling}

Selected sub-sample students (4200 students out of 14, 400 students) accompanying one of their parents were 
referred to the laboratory for blood sampling. Venous blood samples were collected after $12 \mathrm{~h}$ overnight fasting. Centrifugation was done at 2500 to $3000 \mathrm{~g}$ for 10 min. Serum samples were stored at $-70^{\circ} \mathrm{C}$ and transferred to Isfahan Mahdieh Laboratory by cold chain. Fasting blood glucose (FBS), triglycerides (TG), total cholesterol (TC), low-density lipoprotein cholesterol (LDL-C), and high-density lipoprotein cholesterol (HDLC) were measured enzymatically using Hita-chi autoanalyzer (Tokyo, Japan) [23, 24].

Metabolic syndrome was defined according to the Adult Treatment Panel III definition as having at least three of the following abnormalities. 1) abdominal obesity (WC < 90th percentile), 2) low HDL-C (HDL $<40 \mathrm{mg} / \mathrm{dL}$ except in 15-19-year-old boys, in whom the cut-off was $<45 \mathrm{mg} /$ dL), 3) high TG (TG > $100 \mathrm{mg} / \mathrm{dL}), 4)$ high FBG (FBG > $100 \mathrm{mg} / \mathrm{dL}$ ), and 5) high BP (SBP or DBP > 90th percentile adjusted by age, sex, and height) [25]. High LDL-C and high TC were defined as LDL-C $>110 \mathrm{mg} / \mathrm{dL}$ and $\mathrm{TC}>$ $200 \mathrm{mg} / \mathrm{dL}$, respectively [26]. Overweight and obesity were considered as age-sex specific BMI 85th-95th percentile and BMI greater than 95th percentile, respectively [27].

\section{Statistical analysis}

The current study was conducted using a secondary analysis of the CASPIAN-V study. Quantitative variables were expressed as mean (standard deviation) and categorical variables were presented as number (percentage). The Student's $\mathrm{t}$-test was applied to compare mean difference between the means of quantitative variables. Qualitative variables were assessed using Chi-square test. Association of potato and rice consumption with cardiometabolic risk factors was assessed using linear and logistic regression analysis in different models, consisting of Model I: crude model (without adjustment); Model II: adjusted for age, sex, residence area, SES, PA, ST, LNDF (including sweetened beverages and fast foods consumption), and family history of chronic diseases; Model III: additionally adjusted for BMI only for all cardiometabolic risk factors except anthropometric measures. For all models, in the linear and logistic regression analysis, cardiometabolic risk factors were included as continuous and categorical dependent variable in the model respectively. Results of linear and logistic regression model were reported as beta coefficient with standard error (SE) and odds ratio (OR) with the 95\% confidence interval (CI), respectively. The results of the questionnaires were analyzed using clustering analysis to investigate the cluster and design effects. To extrapolate the results to the Iranian children and adolescents, data were weighted directly to the Iranian students according to ministry of education list in 2014, to match the grade (primary/ secondary), sex, and living area (rural/urban). All statistical analyses were performed using STATA package version 11.0 (Stata Statistical Software: Release 11. Stata Corp LP.
Package. College Station, TX, USA) and a $P$-value $<0.05$ was considered statistically significant.

\section{Results}

The participation rates for the whole study and for the blood sampling were 99 and $91.5 \%$, respectively. A total of 14,400 children and adolescents ( $49.9 \%$ girls and $50.4 \%$ boys) with mean age of $12.3 \pm 3.2$ years participated in this study. The frequency of daily consumption of white rice and potato was 84.4 and $21.3 \%$, respectively. Distribution of general characteristics of subjects according to consumption of rice and potato is presented in Supplementary Table 1. Distribution of rice consumption according to living area, level of PA and SES was statistically different $(P<0.050)$. Moreover, association of potato consumption with ST and SES was statistically significant $(P<0.050)$. Table 1 shows the prevalence of cardiometabolic risk factors according to rice and potato consumption. No significant differences were observed between daily and non-daily rice consumers according to prevalence of all cardiometabolic risk factors except high SBP. The prevalence of high SBP in daily potato consumers was significantly higher than non-daily consumers $(3.8 \%$ vs. 2.9\%) (P: 0.01).

Table 2 demonstrates the mean $( \pm \mathrm{SD})$ of anthropometric and cardiometabolic indices according to the rice and potato consumption. The mean values of hip (79.2 \pm 14.5) were significantly higher in subjects with daily rice consumption compared to other participants $(78.5 \pm 14.8)(P<$ 0.050). Diastolic BP was significantly lower in participants with daily rice consumption than non-daily consumption (63.7 \pm 10.4 vs. $64.2 \pm 10.2),(P<0.001)$. There was a significant difference in waist to height ratio between participants with daily potato consumption and non-daily potato consumption $(0.450 \pm 0.06$ vs. $0.458 \pm 0.06)(P<0.001)$.

Association of rice and potato consumption with anthropometric and cardiometabolic indices (as continuous variable) in linear regression analysis is presented in Table 3. Although, in the crude model, daily rice consumer had statistically lower diastolic BP ( $\beta$ : -0.56 , SE: $0.24)$ and $\mathrm{HC}(\beta: 0.74$, SE: 0.34$)$ compare to nondaily consumers, in the multivariable model theses associations were not statistically significant. In the multivariable linear regression model, daily consumption of potato increased significantly BMI ( $\beta$ : 0.05 , SE: $0.2, p=$ $0.010)$, WC ( $\beta$ : 0.63 , SE: $0.24, p=0.008)$, and $\mathrm{HC}(\beta$ : 0.62 , SE: $0.26, P=0.019)$.

Association of rice and potato consumption with overweight, obesity and cardiometabolic risk factors in logestic regression analysis is presented in Table 4 . In the multivariable model, daily consumption of potato significantly increased odds of overweight (OR: 1.21, 95\% CI: 1.04-1.39, $P=0.012$ ). Association of potato and rice consumption with other cardiometabolic risk factors was not statistically significant in the multivariable model ( $p$-value> 0.05 ). 
Table 1 Prevalence of cardio-metabolic risk factors according to rice and potato consumption in Iranian children and adolescents: the CASPIAN-V study

\begin{tabular}{|c|c|c|c|c|c|c|c|}
\hline & \multicolumn{3}{|c|}{ Rice Consumption } & \multicolumn{3}{|c|}{ Potato Consumption } & \multirow[t]{2}{*}{ Total } \\
\hline & Daily (\%) & Nondaily (\%) & $P$-value & Daily (\%) & Nondaily (\%) & P-value & \\
\hline Abdominal obesity & $2506(21.0)$ & $460(21.4)$ & .677 & $658(22.0)$ & $2296(20.8)$ & .151 & $2972(21.1)$ \\
\hline Over weight & $1131(9.5)$ & $197(9.1)$ & 0.630 & $308(10.3)$ & $1007(9.1)$ & 0.053 & $1330(9.4)$ \\
\hline Obesity & $1373(11.5)$ & $240(11.1)$ & 0.629 & $342(11.4)$ & $1268(11.5)$ & 0.917 & 1615 (11.4) \\
\hline High FBS & $143(4.3)$ & $18(3.4)$ & 0.299 & $41(4.6)$ & $120(4.1)$ & 0.467 & $161(4.2)$ \\
\hline High TG & $913(27.6)$ & $151(28.2)$ & 0.793 & $237(26.8)$ & $824(28.0)$ & 0.489 & $1065(27.7)$ \\
\hline High TC & $168(5.1)$ & $21(3.9)$ & 0.247 & $49(5.5)$ & $140(4.8)$ & 0.344 & $189(4.9)$ \\
\hline Low HDL & $976(29.5)$ & $157(29.3)$ & 0.910 & $261(29.5)$ & $867(29.5)$ & 0.970 & $1134(29.5)$ \\
\hline High LDL & $569(17.2)$ & 105 (19.6) & 0.180 & $167(18.9)$ & $506(17.2)$ & 0.245 & $674(17.5)$ \\
\hline High SBP & $365(3.1)$ & $71(3.3)$ & 0.606 & $114(3.8)$ & $318(2.9)$ & 0.010 & $438(3.1)$ \\
\hline High DBP & $1214(10.3)$ & $231(10.7)$ & 0.521 & $321(10.8)$ & $1125(10.3)$ & 0.435 & $1450(10.4)$ \\
\hline High BP & $1350(11.4)$ & 249 (11.6) & 0.848 & $357(12.0)$ & $1240(11.3)$ & 0.324 & 1604 (11.5) \\
\hline MetS & $164(5.1)$ & $24(4.6)$ & 0.626 & $45(5.2)$ & $143(5.0)$ & 0.811 & $188(5.0)$ \\
\hline
\end{tabular}

MetS metabolic syndrome, FBS fasting blood sugar, TC total cholesterol, TG triglycerides, $L D L-C$ low-density lipoprotein cholesterol, $H D L-C$ high-density lipoprotein cholesterol, $B P$ blood pressure;

Defined as above the 85th percentile. Overweight: BMI 85th-95th; obesity: BMI >95th; low HDL: 110 mg/dL; high TG: 100 mg/dL; high TC: > 200 mg/dL; high FBS: $>100 \mathrm{mg} / \mathrm{dL}$; high blood pressure: >90th (adjusted by age, sex, height); Abdominal obesity: WHtR>0.5; MetS, ATP-III criteria;

\section{Discussion}

In this national-wide study, we found significant associations of potato consumption with some cardio-metabolic risk factors. In potato consumers and after adjustment for potential confounders, some risk factors such as BMI, WC, and HC remained significant. The results also revealed that in the multivariable model, daily rice consumption was not associated with cardiometabolic risk factors. Our inability to identity positive associations between rice consumption and alteration of other cardio-metabolic risk factors may be related to change in eating habits of the studied population when body composition such as overweight and obesity is altered. Also, some specific difficulties in evaluating food consumption of children and adolescents such as limitation of the selected dietary survey, underreporting, etc. should be considered as the possible reasons for the mentioned issue.

Table 2 Mean ( \pm SD) of anthropometric and cardio-metabolic indices according to rice and potato consumption

\begin{tabular}{|c|c|c|c|c|c|c|}
\hline & \multicolumn{3}{|l|}{ Rice Consumption } & \multicolumn{3}{|c|}{ Potato Consumption } \\
\hline & Daily Mean (SD) & Nondaily Mean (SD) & $P$-value & Daily Mean (SD) & Nondaily Mean (SD) & $P$-value \\
\hline$\overline{\text { FBS }}$ & $91.7(12.2)$ & $91.0(11.4)$ & 0.231 & $91.6(12.5)$ & $91.6(12.0)$ & 0.889 \\
\hline TG & $88.1(45.9)$ & $87.2(40.4)$ & 0.663 & $87.7(44.9)$ & $88.1(45.3)$ & 0.827 \\
\hline TC & $153.6(27.7)$ & $155.1(25.1)$ & 0.240 & $153.9(28.8)$ & $153.8(27.0)$ & 0.973 \\
\hline HDL & $46.2(9.9)$ & $46.0(9.9)$ & 0.805 & $46.4(10.0)$ & $46.1(9.9)$ & 0.459 \\
\hline LDL & $89.9(22.4)$ & $91.6(20.5)$ & 0.108 & $90.2(23.2)$ & $90.1(21.8)$ & 0.944 \\
\hline SBP & $99.0(13.1)$ & $99.5(12.8)$ & 0.156 & 98.9 (13.8) & $99.2(12.8)$ & 0.335 \\
\hline DBP & $63.7(10.4)$ & $64.2(10.2)$ & 0.023 & $63.6(10.8)$ & $63.8(10.3)$ & 0.175 \\
\hline BMI z- score & $0.01(0.99)$ & $0.00(1.03)$ & 0.832 & $0.02(1.09)$ & $0.00(0.97)$ & 0.155 \\
\hline Waist & $66.7(12.1)$ & $66.4(12.1)$ & 0.239 & $67.0(12.8)$ & $66.6(11.9)$ & 0.119 \\
\hline Hip & $79.2(14.5)$ & $78.5(14.8)$ & 0.030 & $79.4(14.9)$ & $79.0(14.5)$ & 0.155 \\
\hline Wrist & $14.7(1.8)$ & $14.7(1.9)$ & 0.313 & $14.7(2.0)$ & $14.7(1.8)$ & 0.487 \\
\hline Neck & $29.8(3.9)$ & $29.8(4.1)$ & 0.648 & $29.8(4.1)$ & $29.8(3.9)$ & 0.649 \\
\hline WHtR & $0.45(0.06)$ & $0.45(0.06)$ & 0.121 & $0.450(0.06)$ & $0.459(0.06)$ & 0.011 \\
\hline WHR & $0.86(0.19)$ & $0.85(0.16)$ & 0.09 & $0.86(0.17)$ & $0.85(0.15)$ & 0.42 \\
\hline
\end{tabular}

FBS fasting blood sugar, TC total cholesterol, TG triglycerides, LDL-C low-density lipoprotein cholesterol, HDL-C high-density lipoprotein cholesterol, SBP systolic blood pressure, DBP diastolic blood pressure, WC Waist circumference, $H C$ hip circumference, $N C$ neck circumference, BMI body mass index, WHtR waist to height ratio, WHR waist to hip ratio 
Table 3 Association of rice and potato consumption with anthropometric and cardiometabolic indices in linear regression analysis

\begin{tabular}{|c|c|c|c|c|c|c|c|}
\hline & & \multicolumn{3}{|c|}{ Rice (Daily/Nondaily) } & \multicolumn{3}{|c|}{ Potato (Daily/Nondaily) } \\
\hline & & $\bar{\beta}$ & SE & P-value & $\beta$ & SE & $P$-value \\
\hline \multirow[t]{3}{*}{ FBS } & Model 1 & 0.676 & 0.564 & 0.231 & -.065 & .465 & .889 \\
\hline & Model 2 & 0.515 & 0.642 & 0.422 & .021 & .525 & .967 \\
\hline & Model 3 & 0.534 & 0.646 & 0.409 & .000 & .529 & .999 \\
\hline \multirow[t]{3}{*}{ TG } & Model 1 & 0.918 & 2.104 & 0.663 & -.380 & 1.735 & .827 \\
\hline & Model 2 & 0.699 & 2.308 & 0.762 & -.030 & 1.887 & .987 \\
\hline & Model 3 & 0.430 & 2.319 & 0.853 & -.258 & 1.897 & .892 \\
\hline \multirow[t]{3}{*}{ TC } & Model 1 & -1.501 & 1.277 & 0.240 & .035 & 1.053 & .973 \\
\hline & Model 2 & -0.564 & 1.432 & 0.694 & -.094 & 1.170 & .936 \\
\hline & Model 3 & -0.650 & 1.441 & 0.652 & -.205 & 1.179 & .862 \\
\hline \multirow[t]{3}{*}{ HDL-C } & Model 1 & 0.115 & 0.465 & 0.805 & .283 & .382 & .459 \\
\hline & Model 2 & 0.058 & 0.517 & 0.911 & .449 & .422 & .288 \\
\hline & Model 3 & 0.082 & 0.520 & 0.875 & .432 & .425 & .309 \\
\hline \multirow[t]{3}{*}{ LDL-C } & Model 1 & -1.661 & 1.034 & 0.108 & .060 & .852 & .944 \\
\hline & Model 2 & -0.673 & 1.161 & 0.562 & -.305 & .948 & .748 \\
\hline & Model 3 & -0.731 & 1.169 & 0.532 & -.353 & .955 & .712 \\
\hline \multirow[t]{3}{*}{ SBP } & Model 1 & -0.435 & 0.307 & 0.156 & -.261 & .270 & .335 \\
\hline & Model 2 & -0.295 & 0.322 & 0.360 & -.182 & .279 & .515 \\
\hline & Model 3 & -0.236 & 0.317 & 0.456 & -.339 & .275 & .217 \\
\hline \multirow[t]{3}{*}{ DBP } & Model 1 & -0.557 & 0.244 & 0.023 & -.293 & .216 & .175 \\
\hline & Model 2 & -0.442 & 0.266 & 0.096 & -.303 & .231 & .191 \\
\hline & Model 3 & -0.405 & 0.264 & 0.125 & -.387 & .229 & .091 \\
\hline \multirow[t]{2}{*}{ BMI z-score } & Model 1 & -0.005 & 0.023 & 0.832 & .029 & .021 & .155 \\
\hline & Model 2 & -0.016 & 0.024 & 0.502 & .053 & .020 & .010 \\
\hline \multirow[t]{2}{*}{ WC } & Model 1 & 0.334 & 0.284 & 0.239 & .390 & .250 & .119 \\
\hline & Model 2 & 0.218 & 0.272 & 0.423 & .628 & .236 & .008 \\
\hline \multirow[t]{2}{*}{$\mathrm{HC}$} & Model 1 & 0.740 & 0.341 & 0.030 & .428 & .301 & .155 \\
\hline & Model 2 & 0.503 & 0.305 & 0.099 & .621 & .265 & .019 \\
\hline \multirow[t]{2}{*}{ Wrist } & Model 1 & -0.045 & 0.044 & 0.313 & .027 & .039 & .487 \\
\hline & Model 2 & -0.033 & 0.041 & 0.419 & .031 & .036 & .385 \\
\hline \multirow[t]{2}{*}{ NC } & Model 1 & 0.038 & 0.093 & 0.684 & .037 & .082 & .649 \\
\hline & Model 2 & -0.035 & 0.085 & 0.681 & .085 & .074 & .250 \\
\hline \multirow[t]{2}{*}{ WHtR } & Model 1 & 0.002 & 0.002 & 0.121 & .003 & .001 & .011 \\
\hline & Model 2 & 0.001 & 0.002 & 0.572 & .005 & .001 & .001 \\
\hline \multirow[t]{2}{*}{ WHR } & Model 1 & -0.008 & 0.004 & 0.061 & -.003 & .004 & .455 \\
\hline & Model 2 & -0.002 & 0.004 & 0.579 & -.001 & .004 & .718 \\
\hline
\end{tabular}

FBS fasting blood sugar, TC total cholesterol, TG triglycerides, $L D L-C$ lowdensity lipoprotein cholesterol, $\mathrm{HDL}-\mathrm{C}$ high-density lipoprotein cholesterol, SBP systolic blood pressure, DBP diastolic blood pressure, WC Waist circumference, $H C$ hip circumference, NC neck circumference, $B M I$ body mass index, WHtR waist to height ratio, WHR waist to hip ratio

Model 1: Crude Model

Model 2:Adjusted for age, sex, region, SES, PA, ST, family history of chronic diseases, and LNDF (fast foods and sweetened beverages)

Model 3Additionally adjusted for BMI
Numerous studies have revealed that diet composition may play an essential role in development of obesity and its risk factors in adults $[28,29]$. Data regarding the effects of dietary components on development of childhood obesity and related risk factors have so far been inconclusive.

There are some inconsistencies in the studies assessing the relationship between refined grains and CVD risk factors. Some of them found no association [30] and others demonstrated even an increment [31]. Some studies have reported positive associations between white rice consumption and CVD risk factors. According to some reports, higher intake of refined grains is associated with higher risk of type II diabetes [32], stroke [33], and hypertriglyceridemia [34]. However, other studies have found little association [16], with the potential exception of an association between white rice and type 2 diabetes [17]. Indian researchers found that rice, as a major source of carbohydrate, in comparison with other sources of carbohydrates, had a weaker effect on rising TG level [35]. The results of a clinical trial conducted on patients with coronary artery disease showed that after replacing refined rice with legume powder and whole grain products, as a source of carbohydrates, glucose and insulin concentrations changed significantly [36]. Other studies showed that refined grains had no effects on risk of hypertension [37], heart diseases, and diabetes type II $[31,38]$. Also, no significant association was observed between refined grains' intake and concentration of fasting insulin in Framingham Cohort Study [39].

The current study revealed that in subjects who consumed potato on a daily basis, the possibility of overweight increased. Inducing a faster rise in glucose level and insulin response maybe one of the possible mechanisms involved in the observed association. Since energy density is considered as a major factor contributing to overconsumption, explaining the relationship between specific foods consumption and excess weight gain is complex.

To enhance flavor in potatoes, they are mostly prepared by oils and fats. So, nutritional value of potatoes and potato products might be overlooked [30]. Due to confounders such as cooking method and storage, the association between dietary potato intake and health is complex [40]. Despite recent recommendations to consume starchy foods, we should consider the above-mentioned points for daily consumers of potato even in local foods [41].

Mozaffarian et al. evaluated the intake of 13 groups of foods and beverages among adults for 4 years. They found that weight gain was significantly higher in subjects who increased their daily intake of potato chips, potato, sugar-sweetened beverages, and processed meat, as compared with those who increased daily intake of vegetables, whole grains, fruit, yogurt, and nuts [42].

In a study conducted by Dong et al. on 7-13-year-old children, they found that high protein and fiber foods 
Table 4 Association between rice and potato consumption with cardio-metabolic risk factors in logistic regression analysis

\begin{tabular}{|c|c|c|c|c|c|c|c|}
\hline & & \multicolumn{3}{|c|}{ Rice Consumption } & \multicolumn{3}{|c|}{ Potato Consumption } \\
\hline & & OR & $95 \% \mathrm{Cl}$ & $p$-Value & OR & $95 \% \mathrm{Cl}$ & $\mathrm{p}$-Value \\
\hline \multirow[t]{3}{*}{ High FBS } & Model 1 & 1.301 & $.790-2.143$ & .301 & 1.144 & $.796-1.645$ & .467 \\
\hline & Model 2 & 1.123 & $.665-1.898$ & .664 & 1.332 & $.906-1.958$ & .144 \\
\hline & Model 3 & 1.110 & $.657-1.877$ & .697 & 1.308 & $.888-1.927$ & .174 \\
\hline \multirow[t]{3}{*}{ High TG } & Model 1 & .973 & $.794-1.192$ & .793 & .942 & $.795-1.116$ & .489 \\
\hline & Model 2 & .947 & $.756-1.185$ & .633 & .935 & $.775-1.127$ & .479 \\
\hline & Model 3 & .942 & $.752-1.181$ & .607 & .922 & $.764-1.113$ & .398 \\
\hline \multirow[t]{3}{*}{ High TC } & Model 1 & 1.313 & $.827-2.087$ & .249 & 1.175 & $.841-1.641$ & .345 \\
\hline & Model 2 & 1.433 & $.841-2.440$ & .185 & 1.206 & $.835-1.741$ & .318 \\
\hline & Model 3 & 1.418 & $.832-2.417$ & .199 & 1.187 & $.820-1.720$ & .364 \\
\hline \multirow[t]{3}{*}{ Low HDL } & Model 1 & 1.012 & $.828-1.236$ & .910 & 1.003 & $.851-1.183$ & .970 \\
\hline & Model 2 & 1.053 & $.840-1.321$ & .653 & .955 & $.794-1.150$ & .630 \\
\hline & Model 3 & 1.055 & $.840-1.325$ & .645 & .948 & $.786-1.142$ & .571 \\
\hline \multirow[t]{3}{*}{ High LDL } & Model 1 & .854 & $.677-1.076$ & .181 & 1.122 & $.924-1.362$ & .245 \\
\hline & Model 2 & .896 & $.689-1.164$ & .409 & 1.152 & $.930-1.426$ & .195 \\
\hline & Model 3 & .890 & $.685-1.157$ & .383 & 1.152 & $.930-1.427$ & .196 \\
\hline \multirow[t]{3}{*}{ High BP } & Model 1 & .986 & $.854-1.138$ & .848 & 1.065 & $.940-1.207$ & .324 \\
\hline & Model 2 & 1.019 & $.865-1.201$ & .820 & 1.063 & $.925-1.223$ & .389 \\
\hline & Model 3 & 1.034 & $.875-1.221$ & .697 & 1.048 & $.910-1.206$ & .518 \\
\hline \multirow[t]{3}{*}{ Mets } & Model 1 & 1.115 & $.719-1.730$ & .626 & 1.043 & $.739-1.471$ & .811 \\
\hline & Model 2 & 1.087 & $.668-1.768$ & .738 & 1.079 & $.738-1.577$ & .694 \\
\hline & Model 3 & 1.104 & $.667-1.829$ & .700 & 1.014 & $.685-1.501$ & .944 \\
\hline \multirow[t]{2}{*}{ Abdominal obesity } & Model 1 & .976 & $.873-1.092$ & .677 & 1.074 & $.974-1.185$ & .151 \\
\hline & Model 2 & .942 & $.830-1.069$ & .357 & 1.114 & $.999-1.242$ & .052 \\
\hline \multirow[t]{2}{*}{ Overweight } & Model 1 & 1.040 & $.89-1.22$ & .631 & 1.142 & $.99-1.30$ & .053 \\
\hline & Model 2 & 1.029 & $.860-1.230$ & .757 & 1.207 & $1.042-1.399$ & .012 \\
\hline \multirow[t]{2}{*}{ Obesity } & Model 1 & 1.037 & $.896-1.199$ & .629 & .993 & $.875-1.128$ & .917 \\
\hline & Model 2 & .981 & $.831-1.158$ & .820 & 1.098 & $.956-1.262$ & .186 \\
\hline
\end{tabular}

MetS metabolic syndrome, FBS fasting blood sugar, TC total cholesterol, TG triglycerides, LDL-C low-density lipoprotein cholesterol, HDL-C high-density lipoprotein cholesterol, $B P$ blood pressure;

Defined as above the 85th percentile. Overweight: BMI 85th-95th; obesity: BMI >95th; low HDL: $110 \mathrm{mg} / \mathrm{dL}$; high TG: $100 \mathrm{mg} / \mathrm{dL}$; high TC: $>200 \mathrm{mg} / \mathrm{dL}$; high FBS: $>100 \mathrm{mg} / \mathrm{dL}$; high blood pressure: >90th (adjusted by age, sex, height); Abdominal obesity: WHtR>0.5; MetS, ATP-III criteria;

Model 1: Crude Model

Model 2: Adjusted for age, sex, region, SES, PA, ST, family history of chronic diseases, and food habits (fast foods and sweetened beverages)

Model 3: Additionally adjusted for BMI

(dietary components that increase satiety and induce lower glycemic index) are negatively associated with excess weight gain [43].

In the present study, subjects with daily consumption of rice had lower DBP compared to non-daily consumers. The results from recent randomized controlled trials are inconsistent with our findings. They demonstrated that low-carbohydrate diets can decrease systolic and diastolic blood pressure [44, 45]. Weight loss would be the driving factor in decreasing blood pressure levels [46]. The observed association in the current study might be related to cross-sectional design of the study. Also, BP results were averages from only two consequent measurements. This method is not a precise methodology for measuring BP; it might be useful to recognize hypertensive subjects [47].

Our study revealed that daily fast foods and daily rice consumers had higher SES levels which are basically because of the higher price of such food items in Iran. While, daily potato consumers had lower SES because potato is very cheap food item in all parts of Iran. Also, current behavior regarding consumption of sweetened beverages and the possible predictors should be examined by using theory of planed behavior (TPB) in the future.

This study has some specific limitations. First, as a result of cross-sectional nature of the study, the obtained 
associations should be considered with caution. Second, data of portion size, quantification information, and type of consumed potato and rice were not collected in our study. Third, we were not able to estimate energy intake in the current study. Fourth, measurement errors are inevitable due to difficulties in evaluating food consumption of children and adolescents. Also, recall bias might be happen because of using self-reported physical activity questioner. The strengths of this study are its large sample size and novelty in the pediatric age group.

\section{Conclusions}

Daily consumption of potato was significantly associated with higher anthropometric measures whereas rice consumption had no statistically significant association with cardiometabolic risk factors. The prevalence of SBP was significantly higher in daily potato consumers compared to others. Therefore, it is recommended that future research examines the possible obesogenic effects of intake of potato on children and adolescents and also, we should consider this point that the evidence of single foods needs to be considered in the context of the total diet.

Despite numerous difficulties in assessing dietary habits of children and adolescents, such studies should be considered a main basis for devising interventions at an early age.

\section{Supplementary information}

Supplementary information accompanies this paper at https://doi.org/10. 1186/s12872-020-01524-y.

Additional file 1: Supplementary Table 1: General characteristics and some food habits of subjects according to rice and potato consumption in Iranian children and adolescents: the CASPIAN-V study.

Additional file 2.

\begin{abstract}
Abbreviations
Mets: Metabolic syndrome; CVD: Cardiovascular disease; CASPIAN$\checkmark$ : Childhood and adolescence surveillance and Preventlon of adult noncommunicable disease; PA: Physical activity; SES: Family socio-economic status; ST: Screen time; PIRLS: Progress in the international Reading literacy study; PCA: Principle components analysis; BMI: Body mass index; WrC: Wrist circumference; WC: Waist circumference; NC: Neck circumference; HC: Hip circumferences; BP: Blood pressure; SBP: Systolic blood pressure; DBP: Diastolic blood pressure; FFQ: Food frequency questionnaire; LNDF: Low nutrient-dense foods; FBS: Fasting blood glucose; TG: Triglycerides; TC: Total cholesterol; LDL-C: Low-density lipoprotein cholesterol; HDL-C: High-density lipoprotein cholesterol; SE: Standard error; OR: Odds ratio; Cl: Confidence interval; TPB: Theory of planed behavior
\end{abstract}

\section{Acknowledgments}

The authors are thankful of all participants and large team working on this project in different provinces.

\section{Authors' contributions}

$\mathrm{FB}, \mathrm{MQ}, \mathrm{RH}$ : concept; $\mathrm{RH}, \mathrm{MQ}$, MEM, RK: design; $\mathrm{AMG}, \mathrm{ZA}, \mathrm{GS}, \mathrm{KN}$ : data collection or processing; $M Q$, RK: analysis or interpretation; $F B, M Q$ : writing. All authors read and approved the final manuscript.

\section{Funding}

This study was not supported by any fund.
Availability of data and materials

The dataset supporting the conclusions of this article will not be shared publicly, to ensure participants' privacy.

\section{Ethics approval and consent to participate}

The protocol of the study was approved by ethical committee of Isfahan University of Medical Sciences. Also, written informed consent and verbal consent were obtained from parents and students, respectively.

\section{Consent for publication}

Not applicable.

\section{Competing interests}

All authors declare that they have no competing interests.

\section{Author details}

${ }^{1}$ Center of Maritime Health and Society, Department of Public Health, University of Southern Denmark, Esbjerg, Denmark. ${ }^{2}$ Non-communicable Diseases Research Center, School of Medicine, Alborz University of Medical Sciences, Baghestan Blvd, Karaj 31485/56, Iran. ${ }^{3}$ Chronic Diseases Research Center, Endocrinology and Metabolism Population Sciences Institute, Tehran University of Medical Sciences, Tehran, Iran. ${ }^{4}$ Department of Pediatrics, Ahvaz Jundishapur University of Medical Sciences, Ahvaz, Iran. ${ }^{5}$ Student Research Committee, Alborz University of Medical Sciences, Karaj, Iran. ${ }^{6}$ Child Growth and Development Research Center, Research Institute for Primordial Prevention of Non-communicable Disease, Isfahan University of Medical Sciences, Isfahan, Iran.

Received: 17 January 2020 Accepted: 12 May 2020

Published online: 19 May 2020

\section{References}

1. Payab M, Kelishadi R, Hasani SH., et al. Grains and Potato Consumption in Association with Anthropometric Measures and Blood Pressure in Iranian Children and Adolescents: The CASPIAN-IV Study Int J Public Health 2015; 44(1):25-34.

2. Djalalinia S, Qorbani M, Peykari N, Kelishadi R. Health impacts of obesity. Pakistan J Med Sci. 2015;31(1):239.

3. Rahmanian M, Kelishadi R, Qorbani M, Motlagh ME, Shafiee G, Aminaee T, et al. Dual burden of body weight among Iranian children and adolescents in 2003 and 2010: the CASPIAN-III study. Archives Med Sci. 2014;10(1):96

4. Han JCLD, Kimm SY. Childhood obesity. Lancet. 2010;375(9727):1737-48.

5. Amirkalali B, Fakhrzadeh H, Sharifi F, Kelishadi R, Zamani F, Asayesh H, et al. Prevalence of metabolic syndrome and its components in the Iranian adult population: a systematic review and meta-analysis. Iran Red Crescent Med J. 2015;17(12):e247234

6. Morrison JAGC, Woo JG, Wang P. Risk factors for cardiovascular disease and type 2 diabetes retained from childhood to adulthood predict adult outcomes: the Princeton LRC follow-up study. Int J Pediatr Endocrinol. 2012;16(1):6.

7. Kelishadi R, Motlagh ME, Roomizadeh P, Abtahi SH, Qorbani M, Taslimi M, Heshmat R, Aminaee T, Ardalan G, Poursafa P, Karimi M. First report on path analysis for cardiometabolic components in a nationally representative sample of pediatric population in the Middle East and North Africa (MENA): the CASPIAN-III study. Ann Nutr Metab. 2013;62(3):257-65.

8. Kelishadi R, Mozafarian N, Qorbani M, et al. Is snack consumption associated withimeal skipping inichildren andiadolescents? The CASPIAN-IV study. Eat Weight Disord. 2017;22:321-81.

9. Mehrkash M, Kelishadi R, Mohammadian S, Mousavinasab F, Qorbani M, Hashemi ME, Asayesh H, Poursafa P, Shafa N. Obesity and metabolic syndrome among a representative sample of Iranian adolescents. Southeast Asian J Tropical Medicineand Public Health. 2012 May 1;43(3):756.

10. Mikkila VRL, Raitakari OT, Pietinen P, Viikari J. Consistent dietary patterns identified from childhood to adulthood: the cardiovascular risk in young finns study. Br J Nutr. 2005:93(6):923-31.

11. Lutsey PLDD Jr, Kori S, Mayer-Davis E, Shea S, Steffen LM. Whole grain intake and its cross-sectional association with obesity, insulin resistance, inflammation, diabetes and subclinical CVD: the MESA study. Br J Nutr. 2007 98(2):397-405.

12. van de Vijver LP, Van den Bosch LM, van den Brandt PA, Goldbohm RA. Whole grain consumption, dietary fibre intake and body mass index in the Netherlands cohort study. Eur J Clin Nutr. 2009;63(1):31-8. 
13. Bazzano LA, Song Y, Bubes V, Good CK, Manson JE, Liu S. Dietary intake of whole and refined grain breakfast cereals and weight gain in men. Obes Res. 2005;13(11):1952-60.

14. Ramachandran AMR, Snehalatha C. Diabetes in Asia. Lancet. 2010;375(9712): 408-18.

15. Kalantari N GM, Houshiarrad A, Kianfar H, Bondarianzadeh D, Abdollahi M, et al. National Comprehensive Study on Household Food Consumption Pattern and Nutritional Status, IR Iran, 2001-2003. National Report 2005.

16. Akhoundan MSZ, Jandaghi P, Aboeerad M, et al. The Association of Bread and Rice with metabolic factors in type 2 diabetic patients. PLoS One. 2016; 11(12):e0167921.

17. Aune $D$, Norat $T$, Romundstad $P$, Vatten $L$. Whole grain and refined grain consumption and the risk of type 2 diabetes: a systematic review and doseresponse meta-analysis of cohort studies. Eur J Epidemiol. 2013;28(11):845-58

18. Aune D, Keum N, Giovannucci E, Fadnes LT, Boffetta P, Greenwood DC, Tonstad S, Vatten $L$, Riboli E, Norat T. Whole grain consumption and risk of cardiovascular disease, cancer, and all cause and cause specific mortality: systematic review and dose-response meta-analysis of prospective studies. BMJ. 2016;353:i2716.

19. Motlagh ME, Ziaodini H, Qorbani M, et al. Early findings of the Fifth Survey of Childhood and Adolescence Surveillance and Prevention of Adult Noncommunicable Disease: the CASPIAN-V study. Int J Prev Med. 2017;8(1):4.

20. Kelishadi R, Ardalan G, Qorbani M, et al. Methodology and early findings of the fourth survey of childhood and adolescence surveillance and Prevention of adult non-communicable disease in Iran: the CASPIAN-IV study. Int J Prev Med. 2013;4(12):1451-60.

21. Caro DH, Cortés D. Measuring family socioeconomic status: an illustration using data from PIRLS 2006. IERI monograph series. Issues and methodologies in large-scale assessments, vol. 5; 2012. p. 9-33.

22. National High Blood Pressure Education Program Working Group on High Blood Pressure in Children and Adolescents. The fourth report on diagnosis, evaluation, and treatment of high blood pressure in children and adolescents. Pediatrics. 2004;114(Suppl):555-76.

23. MCNamara JRSE. Automated enzymatic standardized lipid analyses for plasma and lipoprotein fractions. Clin Chim Acta. 1987;166:1-8.

24. Friedewald WTLR, Fredrickson DS. Estimation of the concentration of lowdensity lipoprotein cholesterol in plasma, without use of the preparative ultracentrifuge. Clin Chemy. 1972;1972(18):499-502.

25. Zimmet PAG, Kaufman F, Tajima N, Silink M, Arslanian S. The metabolic syndrome in children and adolescents. Lancet. 2007;369(9579):2059-61.

26. Yoon JM. Dyslipidemia in children and adolescents: when and how to diagnose and treat? Pediatr Gastroenterol Hepatol Nutr. 2014;17(2):85-92.

27. Shafiee $G$, Kelishadi R, Qorbani M, et al. Association of breakfast intake with cardiometabolic risk factors. J Pediatr. 2013;89(6):575-82.

28. Langlois KGD, Findlay L. Diet composition and obesity among Canadian adults. Health Rep. 2009;20(4):11-20.

29. Astrup AB-MJ. Diet composition and obesity. Lancet. 2012;379(9821):1100.

30. Mckeown NMMJ, Liu S, Wilson PW, Jacques PF. Whole-grain intake is favorably associated with metabolic risk factors for type 2 diabetes and cardiovascular disease in the Framingham offspring study. Am J Clin Nutr. 2002;76(2):390-8.

31. Liu SMJ, Stampfer MJ, Hu FB, Giovannucci E, Colditz GA, et al. A prospective study of wholegrain intake and risk of type 2 diabetes mellitus in US women. Am J Public Health. 2000;90(9):1409.

32. Nanri AMT, Noda M, Takahashi Y, et al. Rice intake and type 2 diabetes in Japanese men and women: the Japan public health center-based prospective study. Am J Clin Nutr. 2010;92:1468-77.

33. LA Liang W, Binns CW. White rice-based food consumption and ischemic stroke risk: a case-control study in southern China. J Stroke Cerebrovasc Dis. 2010;19:480-4.

34. Esmaillzadeh AMP, Azizi F. Whole-grain intake and the prevalence of hypertriglyceridemic waist phenotype in Tehranian adults. Am J Clin Nutr. 2005;81:55-63.

35. Ezenwaka CEKR. Carbohydrate-induced hypertriglyceridaemia among west Indian diabetic and non-diabetic subjects after ingestion of three local carbohydrate foods. Indian J Med Res. 2005;121:23-31.

36. Jang YL, Kim OY, Park HY, Lee SY. Consumption of whole grain and legume powder reduces insulin demand, lipid peroxidation, and plasma homocysteine concentrations in patients with coronary artery disease. Arteriosclerosis. Thrombosis Vascular Biol. 2001:21:2065-71.
37. Wang LGJ, Liu S, Manson JE, Buring JE, Sesso HD. Whole- and refined-grain intakes and the risk of hypertension in women. Am J Clin Nutr. 2007:86:472-9.

38. Liu SSH, Manson JE, Willett WC, Buring JE. Is intake of breakfast cereals related to total and cause-specific mortality in men? Am J Clin Nutr. 2003. 77:594-9.

39. McKeown NMMJ, Liu S, Saltzman E, Wilson PW, Jacques PF. Carbohydrate nutrition, insulin resistance, and the prevalence of the metabolic syndrome in the Framingham offspring cohort. Diabetes Care. 2004;27(2):538-46.

40. Robertson TM, Alzaabi AZ, Robertson MZ, Fielding BA. Starchy carbohydrates in a healthy diet: the role of the humble potato. Nutrients. 2018;10:1764.

41. Eat Well-NHS.UK. Available online: https://www.nhs.uk/live-well/eat-well/ (Accessed 6 Aug 2018).

42. Mozaffarian DHT, Rimm EB, Willett WC, Hu FB. Changes in diet and lifestyle and long-term weight gain in women and men. N Engl J Med. 2011. 364(25):2392-404

43. Dong DBM, van Dam RM, Finkelstein EA. Consumption of specific foods and beverages and excess weight gain among children and adolescents. Health Aff. 2015;34(11):1940-8.

44. Foster GD, Wyaat HR, Hill JO, et al. Weight and metabolic outcomes after 2 years on a low-carbohydrate versus low-fat diet: a randomized trial. Ann Intern Med. 2010;153:147-57.

45. Frisch S, Zittermman A, Berthold HK, et al. A randomized controlled trial on the efficacy of carbohydrate-reduced or fat-reduced diets in patients attending a telemedically guided weight loss program. Cardiovasc Diabetol. 2009;8:36.

46. Lim SSNM, Keogh JB, Clifton PM. Long-term effects of a low carbohydrate, low fat or high unsaturated fat diet compared to a no-intervention control. Nutr Metab Cardiovasc Dis. 2010;20:599-607.

47. Tighe P, Garry GD, Vaughan N, et al. Effect of increased consumption of whole-grain foods on blood pressure and other cardiovascular risk markers in healthy middle-aged persons: a randomized controlled trial. Am J Clin Nutr. 2010:92:733-40.

\section{Publisher's Note}

Springer Nature remains neutral with regard to jurisdictional claims in published maps and institutional affiliations.
Ready to submit your research? Choose BMC and benefit from:

- fast, convenient online submission

- thorough peer review by experienced researchers in your field

- rapid publication on acceptance

- support for research data, including large and complex data types

- gold Open Access which fosters wider collaboration and increased citations

- maximum visibility for your research: over $100 \mathrm{M}$ website views per year

At $\mathrm{BMC}$, research is always in progress.

Learn more biomedcentral.com/submission 